\title{
TU/e EmonOWEN

\section{Framework for assessing the performance potential of seasonally adaptable facades using multi-objective optimization}

\author{
Citation for published version (APA): \\ Kasinalis, C., Loonen, R. C. G. M., Costola, D., \& Hensen, J. L. M. (2014). Framework for assessing the \\ performance potential of seasonally adaptable facades using multi-objective optimization. Energy and Buildings, \\ 79, 106-113. https://doi.org/10.1016/j.enbuild.2014.04.045
}

DOI:

10.1016/j.enbuild.2014.04.045

Document status and date:

Published: 01/01/2014

\section{Document Version:}

Accepted manuscript including changes made at the peer-review stage

\section{Please check the document version of this publication:}

- A submitted manuscript is the version of the article upon submission and before peer-review. There can be important differences between the submitted version and the official published version of record. People interested in the research are advised to contact the author for the final version of the publication, or visit the DOI to the publisher's website.

- The final author version and the galley proof are versions of the publication after peer review.

- The final published version features the final layout of the paper including the volume, issue and page numbers.

Link to publication

\footnotetext{
General rights

- You may freely distribute the URL identifying the publication in the public portal. follow below link for the End User Agreement:

www.tue.nl/taverne

\section{Take down policy}

If you believe that this document breaches copyright please contact us at:

openaccess@tue.nl

providing details and we will investigate your claim.
}

Copyright and moral rights for the publications made accessible in the public portal are retained by the authors and/or other copyright owners and it is a condition of accessing publications that users recognise and abide by the legal requirements associated with these rights.

- Users may download and print one copy of any publication from the public portal for the purpose of private study or research.

- You may not further distribute the material or use it for any profit-making activity or commercial gain

If the publication is distributed under the terms of Article $25 \mathrm{fa}$ of the Dutch Copyright Act, indicated by the "Taverne" license above, please 


\title{
Framework for assessing the performance potential of seasonally adaptable facades using multi-objective optimization
}

\author{
C. Kasinalis, R.C.G.M. Loonen ${ }^{\bowtie}$, D. Cóstola, J.L.M. Hensen \\ Building Physics and Services, Eindhoven University of Technology, the Netherlands
}

\begin{abstract}
Climate adaptive building shells (CABS) are receiving increasing attention because they can enable highperformance building design that combines low energy consumption with good indoor environmental quality (IEQ). Various studies have acknowledged the potential of CABS with seasonal adaptation, but thus far, there is no method available to quantify their performance potential. This paper presents a framework for design and performance analysis of CABS with optimal seasonal adaptation strategies. The framework is based on a sequence of multi-objective optimization scenarios and uses a genetic algorithm in combination with coupled building energy and daylighting simulations. Findings from a case study with an office building in the Netherlands demonstrate the effectiveness of the framework in quantifying the potential of seasonal CABS. Results of the case study show that monthly adaptation of six facade design parameters can lead to improved IEQ conditions and 15-18\% energy savings compared to the best performing non-adaptive building shell. Through post-optimization analysis of monthly and annual solutions, a better understanding of the key elements of seasonal facade adaptation is obtained.
\end{abstract}

Keywords: Climate adaptive building shell, seasonal facade adaptation, building performance simulation, multiobjective optimization

\footnotetext{
Corresponding author:

e-mail: $\quad$ r.c.g.m.loonen@tue.nl

phone: +31402472571

postal address: Roel Loonen

Eindhoven University of Technology

P.O. Box $5135600 \mathrm{MB}$

Eindhoven, The Netherlands
} 


\section{Introduction}

There is a growing interest for buildings with adaptable facade elements which are capable of dynamically adjusting their properties in response to variable ambient conditions and occupants' comfort preferences [1-5]. Through enhanced interaction with the environment, climate adaptive building shells (CABS) seek the reduction of energy demand for heating, cooling and lighting, while maintaining high levels of indoor environmental quality [6].

So far, most attention has been given to research, design and development of CABS that can change their properties on a high-frequency basis, e.g., seconds, minutes or hours [7]. Examples include the deployment of switchable glazing technology [8], dynamic thermal insulation [9], advanced solar shading systems [10-12], and materials with variable solar absorptance/emittance properties [13]. These short-term adaptation mechanisms enable the facade to change in direct response to the varying conditions, and as a result, they are expected to present the highest potential in terms of performance improvements [14-16]. In terms of complexity, however, the application of short-term CABS is often assessed as less favorable because it typically requires relatively complex and expensive technologies [6]. Moreover, the control of short-term CABS in the operational phase is rarely a trivial task, and problems during operation may have an adverse effect on CABS performance [17-19]. In view of these aspects, it can be argued that in many construction projects the option of short-term CABS is regarded as inferior to more conventional facade technologies [20].

An alternative to short-term CABS are facades that can adapt their behavior in response to changing conditions over the seasons [21]. Previous studies have indicated that building designs with seasonal adaptation strategies can, in principle, enhance energy and comfort performance compared to the best static situation. Improvements in building performance have been demonstrated in cases with seasonal variation in, for example: solar shading design [22-24], window properties [25-29], thermal insulation [30], thermal mass [31], natural ventilation strategies [32,33] and temperature set points [34]. Compared to short-term adaptability, the feasibility of long-term CABS is expected to be higher, as long-term CABS are more likely to be built as low-cost add-on solutions, with less challenging technologies and simpler controls [14].

Despite the promising perspective, there is still little information available that quantifies the relationship between long-term adaptable facade principles and potential building performance improvements. No study has addressed this issue from a higher-level perspective, focused on a methodology to quantify the performance potential of seasonal building shell adaptation. This potential must be based on optimum adaptable building shell 
properties, but there is no method available to guide designers towards a systematic and effective assessment of optimum long-term CABS properties.

This paper presents a method for quantifying the impact of seasonal facade adaptation on building performance, based on coupled building energy and daylight simulations, conducted under multi-objective optimization (MOO) scenarios with genetic algorithms. This method is described by means of a case study, which assesses the improvement in energy performance and indoor environmental quality due to monthly adaptation of six building envelope parameters. The work in this paper aims to increase understanding of the feasibility of long-term adaptable facades as a design strategy, by analyzing the mutual influence between design and performance aspects from a higher-level perspective, i.e. the potential of long-term CABS concepts. Actual implementation aspects and specifics of innovative materials and building envelope components are not within the scope of this study, but could be explored on the basis of the results we present here.

This paper is structured in four sections, as follows. Section 2 describes the methodology adopted for the quantification of long-term CABS performance in the case study, including details of the case study building, performance indicators and strategies for simulation and optimization. In Section 3, results of the case study are presented and analyzed. Finally, Section 4 reflects on the findings of this work, and provides directions for future research.

\section{Methodology}

\subsection{Case Study Building Model}

The zone under investigation (Figure 1) is a single-person south facing perimeter office zone ( $3.6 \mathrm{~m} \times 5.4 \mathrm{~m} \mathrm{x}$ $2.7 \mathrm{~m}$ ). The zone is situated at an intermediate floor and surrounded by identical office zones and a corridor at the back. The building, which is evaluated under Dutch climate conditions, is occupied on weekdays from 8 to 17 hours. Heating is supplied with an ideal system with unlimited capacity, but no active cooling system is employed. Ventilation with outside air (no heat recovery) is provided at a rate of $2 \mathrm{ACH}$ during occupied hours. The opaque part of the external facade is modeled as a single layer with a thickness of $0.35 \mathrm{~m}$. Window-to-wall ratio (WWR) as well as thermophysical and optical material properties are determined by optimization. Table 1 gives the adaptable design parameters, together with the upper and lower bounds.

$<$ Figure 1 > 
$<$ Table 1 $>$

Allowing the different glazing properties to vary independently from each other can easily lead to fenestration typologies that are unrealistic from a physical point of view. To avoid this, we used existing window systems with meaningful properties. Table 2 shows the detailed properties of the glazing types that correspond to the glazing IDs from Table 1.

$<$ Table 2>

An external shading system is applied to control the solar gains. Venetian blinds are "ideally" controlled on the basis of an active users profile [35]. This stochastic algorithm assumes that the blinds are rearranged on a regular basis with the aim of maximizing daylight availability while preventing glare and direct sunlight on the work plane [35]. Artificial lighting with a lighting power density of $10 \mathrm{~W} / \mathrm{m}^{2}$ is switched on/off, only when daylight availability is not sufficient to meet the illuminance target of 500 lx on the work plane (Figure 1).

\subsection{Performance Indicators}

\subsubsection{Energy Performance}

The energy saving potential of the investigated case study is assessed by considering the zone's primary total energy consumption, which is composed of the energy required for heating (central heating efficiency factor 0.65 ) and artificial lighting electricity (power plant efficiency factor 0.4). An active cooling system is not considered in this case study, therefore cooling energy does not contribute to the energy demand. Energy consumption for artificial lighting is not fixed during the operation of the office but varies with daylight availability in accordance with the different building shell configurations.

\subsubsection{Indoor Environmental Quality}

Thermal comfort is evaluated using an adaptive thermal comfort (ATC) indicator [36]. The method is mainly intended to assess naturally conditioned spaces, like the office investigated, and presents specific advantages over the more traditional comfort metrics, which make it an appropriate indicator for high-performance building design in moderate climates $[37,38]$. As the heating system is assumed to have unlimited capacity, there is no 
thermal comfort problem regarding heating. The building has no active cooling system, and thermal comfort performance is measured by the number of overheating hours during occupied hours.

The heating system in the zone is controlled on the basis of indoor air temperature, with a set point $0.5^{\circ} \mathrm{C}$ above the lower acceptable indoor temperature threshold for comfort class II [39] from 7-17 hours, and a set point of $17^{\circ} \mathrm{C}$ when the office is unoccupied.

Visual comfort requirements are indirectly taken into account through the operation of artificial lighting and blinds; the blinds are operated with the aim of maximizing daylight availability while preventing direct sunlight on the work plane. This guarantees that minimum lighting levels are provided during operation hours and glare is avoided, so visual comfort conditions are always met.

\subsection{Simulation strategy}

Dynamic building performance simulations (BPS) were conducted using the multi-zone building model in TRNSYS [40]. These energy simulations in TRNSYS were coupled with the outcomes of daylight simulations in DAYSIM [41]. Daylight simulations were conducted in a preprocessing stage for all the daylight opening configurations. During simulation run-time, data generated by DAYSIM (such as time-series of blinds' states and artificial lighting use (on/off), together with occupants' presence) were coupled to TRNSYS, according to the selected visual and daylight requirements [42].

The long-term adaptation was investigated using twelve separate analyses, where each month of the year was addressed by a different set of simulations and optimization. The annual performance was then obtained by the combination of monthly results, as described in detail in Section 2.5.

\subsection{Optimization strategy}

The coupling of BPS tools with evolutionary optimization algorithms has proven to be a valuable approach for efficient and effective exploration of the option space in building envelope design [43-48]. Particularly in supporting high-performance building design, the application of multi-objective optimization (MOO) algorithms is useful [49-51], as it allows for visualization of trade-offs between two or more conflicting design objectives $[52,53]$. The main advantage of this approach is that best trade-off solutions are represented as a set of equally optimum solutions, the Pareto front, from which a single design can be selected a posteriori, by taking the decision-maker's priorities into account. 
In our application example, bi-objective MOO is first applied on an annual basis with fixed envelope properties in order to define a reference case, i.e. an optimum non-adaptive facade. Then, a series of analyses is conducted with an optimization horizon of one month. In this way, performance optimization of monthly adaptive building envelopes becomes feasible, but it also allows for deriving optimal facade behavior on a longer scale (e.g. seasonal)

The optimization process is carried out using the non-dominated sorting genetic algorithm II (NSGA-II). In each optimization run, an initial population of 30 samples out of a pseudo-random Sobol sequence was used. A maximum of 3000 iterations was used as stopping criterion.

The two optimization objectives to be minimized are:

- The primary energy consumption $\left[\mathrm{kWh} / \mathrm{m}^{2}\right]$ (sum of the heating and artificial lighting)

- The number of hours per year when $\left|\mathrm{T}_{\text {diff }}\right|>3 \mathrm{~K}$, where $T_{\text {diff }}$ is the temperature difference between the indoor operative temperature $\left(\mathrm{T}_{\mathrm{op}}\right)$ and the comfort/neutral $\left(\mathrm{T}_{\text {comf }}\right)$ temperature (Category II in Standard EN 15251)

\subsection{Optimum annual performance by combining monthly optimized solutions}

The division of the year in twelve monthly optimization horizons gives rise to the creation of twelve different Pareto fronts with monthly optimized solutions. The performance of adaptable building shell concepts on an annual basis can be explored by combining the results from separate months. The optimal adaptable annual solutions are obtained by making all the possible summations of only the Pareto-optimal points of the different months.

As shown in Figure 2, the Pareto front of each month $\mathbf{i}$ consists of $\mathbf{n}_{\mathbf{i}}$ monthly optimum solutions $\mathbf{x}_{\mathbf{i j}}$, where

$$
\begin{aligned}
& i=1,2 \ldots 12 \\
& j=1,2, \ldots . n_{i}
\end{aligned}
$$

Making all the possible combinations of the points $\mathbf{x}_{\mathrm{ij}}$ of each month, results in a cloud of possible annually optimal solutions, which comprises $\mathbf{M}$ new points:

$$
M=n_{1} \times n_{2} \times \ldots \times n_{12}
$$

Each of these new solutions $\mathbf{y}_{\mathbf{k}}$ represents the annual performance of one of the possible summations between the monthly Pareto solutions: 


$$
\begin{gathered}
y_{k}=x_{1 j}+x_{2 j}+\ldots+x_{12 j} \\
k=1,2, \ldots . M
\end{gathered}
$$

The Pareto front of the newly created cloud of annual optimum design solutions describes the optimum performance of a building shell that changes its facade properties every month. It is shown in Figure 3.

$<$ Figure 2>

$<$ Figure 3 $>$

\section{Analysis of the results}

\subsection{Optimum annual performance with static facade}

Figure 4 shows the performance of the case study when the static building envelope is optimized for a whole year. The design options are evaluated for energy performance (horizontal axis) and indoor environmental quality (vertical axis) according to the optimization objectives as described in Section 2.4. In this graph, each dot represents the performance corresponding to a single building design. The Pareto-optimal design solutions are indicated in black.

\section{$<$ Figure 4>}

From Figure 4, it can be observed that the design of the building envelope has a strong influence on both energy and comfort performance. An interesting point derives from the shape of the Pareto front; the steepness of the slope is relatively high compared to other studies with similar optimization objectives (e.g. [54,55]).In previous research, it has been demonstrated that the choice of thermal comfort indicator has significant impact on building performance optimization outcomes $[56,57]$. The high steepness of the Pareto front in the case study can be partially attributed to the thermal comfort index adopted.

Results in Figure 4 also indicate a relatively weak conflict situation between the objectives, as energy consumption plays a major role in the winter and thermal discomfort in the summer. The remaining conflict between these performance indicators occurs in the mid-seasons and part of the summer, where daylight 
contributes to energy saving for heating and artificial lighting but may increase thermal discomfort due to higher heat gains by solar radiation.

Overall annual energy consumption of optimized design solutions lies in a range between 70 and 95 $\mathrm{kWh} / \mathrm{m}^{2}$.y. Such values are in line with the typical energy consumption of state of the art office buildings in the Netherlands [58]. Optimized results in Figure 4 constitute a baseline for energy consumption for heating and lighting in this case study. Facade design with properties in the ranges given in Table 1 and Table 2 does not lead to energy consumption lower than this threshold.

\subsection{Optimum monthly performance of CABS}

Figure 5 shows results of monthly design optimization for the months April and August, as an example of the results obtained for all twelve months of the year.

\section{$<$ Figure 5 $>$}

In both months, the competitive nature of the selected optimization objectives is revealed. In April, the risk for overheating in the optimized solutions tends to be lower (up to 56 hours), whereas in August, less energy is needed but overheating can reach higher values (up to 110 hours). Such findings signal the potential for building envelopes configured in response to these variable seasonal conditions, and as such confirm the rationale behind CABS. Moreover, results in Figure 5 show the advantages of using Pareto fronts in $\mathrm{MOO}$ in comparison to the a priori weighted sum of different performance indicators. The balance, or compromise, between the two performance criteria changes over time. Only the Pareto approach allows the decision maker to use this information for navigating between the different regions of interest.

In addition to the results presented in Figure 5, it needs to be mentioned that during winter months (October until March) the reduced overheating risk simplifies the optimization task to a quasi-single-objective problem.

Results presented in this subsection only show some of the monthly optimized performance; therefore the comparison to the annual results from Figure 4 is not yet possible. In the next subsection, the Pareto fronts of the twelve months of the year are combined in a single annual plot following the method proposed in this paper and described in Section 2.5. 


\subsection{Optimum annual performance of seasonal CABS}

After the optimization of the office's performance for every month is done, it is possible to examine the potential of monthly building shell adaptation. The optimal annual performance of such a building shell is again represented by a cloud of possible solutions. For the case study, this cloud is shown in Figure 6 with pink dots, with its corresponding Pareto set in red. For comparative reasons, the set of optimized solutions for the static building shell (Figure 2) is represented with black dots in Figure 6. It is worth noting that all solutions that were aggregated from the sets of monthly optimal results are non-dominated with respect to the Pareto-optimal design solutions with a static facade.

Due to the large number of possible combinations originating from the points in the twelve Pareto fronts, the density of the created cloud is significant. Therefore, it is more difficult to distinguish individual solutions (dots) in comparison with the cloud representing the performance of the same zone with a non-adaptive facade. This finding indicates that many CABS solutions lead to approximately similar performance, and that additional preferences could be introduced to select the best alternative.

\section{$<$ Figure 6>}

When evaluated under only the scope of energy consumption reduction, the application of a monthly adaptable facade shows some improvement. For example, if the design team accepts discomfort in the range of 240 hours per year (EN 15251,category II), then the reduction in energy consumption amounts to $18 \%$ compared to the best performing static building shell design (points B and B'). This saving potential is not remarkably high, but it should be considered that these savings are compared to an optimized static facade, and most buildings do not have optimized static facades. Moreover, savings around $18 \%$ would provide, for example, four credits in the LEED certification, which is a good result considering that the intervention is focused only on seasonal adaptability of the building envelope.

The potential of seasonal CABS stands out better when not only the effects on energy conservation, but concurrently also the impact on indoor environmental quality is considered. The office zone with adaptive features achieves a high-quality indoor environment (up to zero discomfort hours, point C) while achieving energy savings around $15 \%$ in comparison with the best performing static design, point $\mathrm{B}^{\prime}$. This performance gain points out that further developments of innovative adaptable building shell concepts are justifiable, 
particularly considering the positive correlation between indoor environmental quality and increased employee productivity in office spaces $[59,60]$.

\subsection{Optimum properties of seasonal CABS}

In addition to the assessment of the performance potential of a building shell with monthly adaptable properties, it is also useful to gain better understanding of the optimum design characteristics of such an innovative facade. Figure 7 shows the time evolution of optimal WWR values for the three representative points of Figure 6. The three lines represent point B (with 240 discomfort hours), and the two Pareto extremes with maximum (point A) and minimum discomfort level (point C). The fixed value of the best performing static facade design point $\mathrm{B}^{\prime}$ is indicated with the dashed line.

\section{$<$ Figure 7>}

Figure 7 shows a clear preference for low WWR values during winter months. This result implies, in accordance with previous research $[46,51,61]$, that under temperate winter conditions, passive solar gains and daylight utilization are insufficient to compensate for conduction losses. Due to the lower thermal resistance of fenestration compared to opaque wall parts, the given optimization formulation consistently favors low window to wall ratios in winter. In mid-season months, however, the reduced heating demand in combination with the low risk for overheating promotes higher levels of daylight utilization. Therefore, relatively high values of WWR are the optimum during these months. In the summer period, the substantially higher risk of thermal discomfort leads to smaller window areas than in the mid-season, but larger in comparison to winter months.

The differences in performance between points A, B and C in Figure 7 are clearly reflected in the optimum WWR for each case. During the winter months all three points have the same values due to the mild conflict between performance objectives as discussed in Section 3.2. During the mid-season and summer, two groups can be identified. On one hand, the designs with priority in energy consumption (points A and B) have larger windows, reducing the use of artificial lighting but increasing the overheating hours. On the other hand, the design with priority for comfort (point C) has reduced windows sizes, spending more energy for artificial lighting but avoiding comfort problems. The decision between the two design variants is essentially dependent on the priorities of the design team about a specific building zone. 
A comparison between the properties of point B and the static optimum shell (B' represented by the dashed line) in Figure 7 shows that the improvements in performance are based on a strong adaptation in WWR. It is remarkable that, for most months in the year, the adaptable WWR values are larger than the static value. Larger WWR values indicate that in this case study CABS also increase the view to the outside, which is an important performance aspect in buildings [62]. As such, this finding shows a clear example of the promising role of CABS, together with the type of concessions [63] that is needed to design static building envelopes which are supposed to perform well under the wide range of different boundary conditions.

Figure 7 also provides useful information regarding the frequency of adaptation in CABS. Using monthly optimum results, the seasonal adaptation is highlighted. WWR values, for example, remain fixed over the whole winter whereas in warmer months, more frequent adaptation is preferred. Nevertheless, the most suitable frequency for CABS adaptation shall be addressed by simultaneously evaluating the variation of all design parameters and variations in performance associated with this adaptation. This paper is not focused on the analysis of optimum adaptation frequencies for seasonal CABS, and this issue should be addressed in future work.

$<$ Figure 8>

Figure 8 presents the optimum monthly values of the other building shell properties in the case study. The overall trend for most properties is in accordance with the expected behavior. External surface absorptance has higher values in winter (improving solar gains) and has lower values in the summer (reflecting solar radiation). Thermal conductivity has lower values in the winter and mid-season (reducing conduction losses) and has higher values in summer to improve thermal losses and avoid overheating. The combined effects of density and specific heat create a lightweight building in the winter and heavyweight in the summer. Finally, the evolution of glazing ID over time points out that it is important to have high-performance fenestration properties, i.e. low U-value $\left(0.9 \mathrm{~W} / \mathrm{m}^{2} \mathrm{~K}\right)$ and relatively low g-value $(0.59)$, throughout the entire year. The effects of glazing ID is closely related to the optimum value of WWR, and further investigation is needed regarding the trade-off between these two variables.

Monthly optimized CABS properties in Figure 8 also show some erratic behavior that might not be directly the result of physical principles. Part of this behavior may be caused by limitations of the genetic algorithm, 
which cannot guarantee that the outcome of the optimization process is the global optimum. Although measures have been taken to ensure convergence of the optimization, an in-depth analysis of the impact of different settings of the algorithm was not the focus of this research. These results, however, demonstrate the need for further research on robustness of optimization outcomes with respect to CABS.

Another reason for the erratic behavior of some properties pertains to sensitivities in the input-output relationship between design parameters and objectives. Two different effects play a role here:

1. There is an inherent difference in sensitivity of the performance indicators to each CABS property in the design option space $[64,65]$.

2. The effect of certain design variables (e.g. solar absorptance) can become negligible when another variable (e.g. thermal insulation) has a first-order effect in driving the optimization [66].

The different role of properties on the performance of CABS is further exemplified in Figure 9 which reproduces the same results as presented in Figure 5; i.e. the cloud of design options investigated during optimization for the month of April. In Figure 9, each design alternative is colored according to the value of the conductivity (Figure 9a) and specific heat capacity (Figure 9b). As far as thermal conductivity is concerned (Figure 9a), it can be noticed that design solutions converge to a specific tint of the color map as the design solutions approach the Pareto front. Such kind of ordered patterns in the optimization cloud and along the front contain useful cues about the significance of design variables to the optimal trade-off in multi-objective problems [66]. Based on results in Figure 9a, conductivity seems to have a dominant influence on performance as all Pareto-optimal solutions converge to approximately the same value. This dominant effect reduces the erratic behavior of this property in the optimization results, as seen in the winter months of Figure 8b. This is in contrast with the random spread of values in the Pareto front for specific heat capacity, and in this case the optimum solution in Figure 8d should be adopted with caution. The selection of optimization variables and their role in the optimized solution is not the main focus of this paper, and this issue should be addressed in future work.

<Figure 9> 


\section{Concluding remarks}

The goal of this paper was to introduce a method for quantifying the impact of seasonal facade adaptation on building performance, based on coupled building energy and daylight simulations, conducted under specific multi-objective optimization (MOO) scenarios with genetic algorithms. The proposed method also addresses the combination of monthly Pareto fronts, providing an effective instrument for the quantification of their annual performance. In the present case study, the concept of seasonal adaptability of building facades indicates potential advantages as it can offer energy savings while upgrading the indoor environment. Specifically, this study shows that a south facing office zone with a monthly adaptive facade in the Dutch climate can have up to $15 \%$ energy savings and largely improved thermal comfort conditions in comparison with the best performing non-adaptive facade. View to the outside is also improved in the case with adaptive facade, as higher values of WWR are achieved in most of the year. Regarding the design characteristics of such an optimized adaptive facade, results show a strong relationship between some of the variables and the seasonal boundary conditions. Analysis of optimization results with colored scatter plots is a powerful tool to visualize such relationship.

While this paper proposes a way for optimizing the performance of adaptable building shells, there are many issues related to practical implementation that were not addressed. In this paper, the subject is approached from a high-level perspective, without analyzing the details of specific climate adaptive building shells (CABS) concepts. The method, however, can also be applied to assist in the product development of innovative facade components, or to support the design process of specific buildings with seasonal CABS.

It is evident that the application of adaptive instead of conventional envelopes entails a higher level of complexity during the design, construction and operational phase. One of the next steps towards better understanding the nature of such innovative buildings relates to the reduction of complexity of CABS solutions with the help of building performance simulation. As indicated along this paper, a more thorough analysis of the input-output relationships and robustness of optimized adaptable facade design variables could be of great assistance since it may reveal crucial information about which variables are worth being considered as adaptable or fixed over the building's lifetime. Additionally, it can help in reducing complexity by identifying the optimum time periods in which adaptation of certain properties has the biggest effect. Addressing the challenge of simplifying adaptive actions as much as possible, while keeping the corresponding compromise in performance to a minimum, is a relevant direction for future research. 


\section{References}

[1] P. Heiselberg, ed., IEA ECBCS Annex 44 Integrating Environmentally Responsive Elements in Buildings - Expert Guide Part 1: Responsive Building Concepts, 2009.

[2] B.P. Jelle, A. Hynd, A. Gustavsen, D. Arasteh, H. Goudey, R. Hart, Fenestration of today and tomorrow: A state-of-the-art review and future research opportunities, Solar Energy Materials and Solar Cells. 96 (2012) 1-28.

[3] D. Kolokotsa, D. Rovas, E. Kosmatopoulos, K. Kalaitzakis, A roadmap towards intelligent net zero- and positive-energy buildings, Solar Energy. 85 (12) (2011) 3067-3084.

[4] G. Quesada, D. Rousse, Y. Dutil, M. Badache, S. Hallé, A comprehensive review of solar facades. Transparent and translucent solar facades, Renewable and Sustainable Energy Reviews. 16 (5) (2012) 2643-2651.

[5] S.B. Sadineni, S. Madala, R.F. Boehm, Passive building energy savings: A review of building envelope components, Renewable and Sustainable Energy Reviews. 15 (8) (2011) 3617-3631.

[6] R.C.G.M. Loonen, M. Trčka, D. Cóstola, J.L.M. Hensen, Climate adaptive building shells: state-of-theart and future challenges, Renewable and Sustainable Energy Reviews. 25 (2013) 483-493.

[7] M. Wigginton, J. Harris, Intelligent Skins, Butterworth-Heinemann, Oxford, 2002.

[8] R. Baetens, B.P. Jelle, A. Gustavsen, Properties, requirements and possibilities of smart windows for dynamic daylight and solar energy control in buildings: A state-of-the-art review, Solar Energy Materials and Solar Cells. 94 (2) (2010) 87-105.

[9] F. Burdajewicz, A. Korjenic, T. Bednar, Bewertung und Optimierung von dynamischen Dämmsystemen unter Berücksichtigung des Wiener Klimas, Bauphysik. 33 (1) (2011) 49-58.

[10] M. Kemp, M. Fox, Interactive architecture, Princeton University Press, New York, 2009.

[11] M. Schumacher, O. Schaeffer, M. Vogt, Move: Architecture in Motion - Dynamic Components and Elements, Birkhäuser, Basel, 2010.

[12] Z. Drozdowski, The Adaptive Building Initiative: The Functional Aesthetic of Adaptivity, Architectural Design. 81 (6) (2011) 118-123.

[13] M. Santamouris, A. Synnefa, T. Karlessi, Using advanced cool materials in the urban built environment to mitigate heat islands and improve thermal comfort conditions, Solar Energy. 85 (12) (2011) 30853102 .

[14] D. Claridge, Window management and energy savings, Energy and Buildings. 1 (1) (1977) 57-63.

[15] M. Davies, A wall for all seasons, RIBA Journal. 88 (2) (1981) 55-57.

[16] S. Selkowitz, V. Bazjanac, Thermal performance of managed window systems, ASHRAE Transactions. 85 (1981) 392-408.

[17] J. Moloney, Designing Kinetics for Architectural Facades: State Change, Routledge, 2011.

[18] S. Stevens, Intelligent Facades: Occupant Control and Satisfaction, International Journal of Sustainable Energy. 21 (2001) 147-160.

[19] M. Meagher, Dynamic Ornament: The Design of Responsive Architectural Environments, PhD Thesis, École Polytechnique Fédérale de Lausanne, 2010. 
[20] U. Knaack, Facades - Principles of Construction, Birkhäuser, 2007.

[21] R.C.G.M. Loonen, M. Trčka, J.L.M. Hensen, Exploring the potential of climate adaptive building shells, in: Proceedings of Building Simulation 2011, Sydney, Australia, 2011: pp. 2148-2155.

[22] M. Dubois, The design of seasonal awnings for low cooling and heating loads in offices, in: Proceedings of the 5th Symposium on Building Physics in the Nordic Countries, Göteborg, 1999: pp. 505-512.

[23] N. Bouchlaghem, Optimising the design of building envelopes for thermal performance, Automation in Construction. 10 (1) (2000) 101-112.

[24] K. Ip, M. Lam, A. Miller, Shading performance of a vertical deciduous climbing plant canopy, Building and Environment. 45 (1) (2010) 81-88.

[25] H. Ye, X. Meng, L. Long, B. Xu, The route to a perfect window, Renewable Energy. 55 (2013) $448-455$.

[26] D. Feuermann, A. Novoplansky, Reversible low solar heat gain windows for energy savings, Solar Energy. 62 (3) (1998) 169-175.

[27] Y. Etzion, E. Erell, Controlling the transmission of radiant energy through windows: a novel ventilated reversible glazing system, Building and Environment. 35 (5) (2000) 433-444.

[28] W. Lorenz, Design guidelines for a glazing with a seasonally dependent solar transmittance, Solar Energy. 63 (1998) 79-96.

[29] D.R. Roberts, Preliminary Assessment of the Energy-Saving Potential of Electrochromic Windows in Residential Buildings, National Renewable Energy Laboratory, Technical Report NREL/TP-550-46916, 2009.

[30] P.A. Ruyssevelt, J. Littler, Movable window insulation, Final Report - EUR 9996 EN, 1985.

[31] P. Hoes, M. Trcka, J.L.M. Hensen, B. Hoekstra Bonnema, Investigating the potential of a novel lowenergy house concept with hybrid adaptable thermal storage, Energy Conversion and Management. 52 (6) (2011) 2442-2447.

[32] C.A. Short, K. Lomas, Exploiting a hybrid environmental design strategy in a US continental climate, Building Research \& Information. 35 (2)(2007) 119-143.

[33] J. Joe, W. Choi, H. Kwon, J.H. Huh, Load characteristics and operation strategies of building integrated with multi-story double skin facade, Energy and Buildings. 60 (2013) 185-198.

[34] S.A. Al-Sanea, M.F. Zedan, Optimized monthly-fixed thermostat-setting scheme for maximum energysavings and thermal comfort in air-conditioned spaces, Applied Energy. 85 (5) (2008) 326-346.

[35] C.F. Reinhart, Lightswitch-2002: a model for manual and automated control of electric lighting and blinds, Solar Energy. 77 (1) (2004) 15-28.

[36] F. Nicol, M. Humphreys, Derivation of the adaptive equations for thermal comfort in free-running buildings in European standard EN15251, Building and Environment. 45 (1) (2010) 11-17.

[37] P. Tuohy, S. Roaf, F. Nicol, M. Humphreys, A. Boerstra, Twenty first century standards for thermal comfort: fostering low carbon building design and operation, Architectural Science Review. 53 (1) (2010) 78-86.

[38] J. van Hoof, J.L.M. Hensen, Quantifying the relevance of adaptive thermal comfort models in moderate thermal climate zones, Building and Environment. 42 (1) (2007) 156-170. 
[39] EN 15251, CEN Standard EN 15251: Indoor Environmental Input Parameters for Design and Assessment of Energy Performance of Buildings Addressing Indoor Air Quality, Thermal Environment, Lighting and Acoustics, (2007).

[40] TRNSYS v17 - Volume 5 Multizone Building modeling with Type56 and TRNBuild, (2010).

[41] C. Reinhart, Tutorial on the use of Daysim simulations for sustainable design. National Research Council Canada (NRCC), (2009).

[42] R.C.G.M. Loonen, M. Trčka, D. Cóstola, J.L.M. Hensen, Performance simulation of climate adaptive building shells - Smart Energy Glass as a case study, in: Proceedings of SSB 2010: 8th International Conference on System Simulation in Buildings, Liège, 2010.

[43] C.J. Hopfe, Uncertainty and sensitivity analysis in building performance simulation for decision support and design optimization, PhD Thesis. Eindhoven University of Technology, 2009.

[44] S. Attia, M. Hamdy, W. O’Brien, S. Carlucci, Assessing gaps and needs for integrating building performance optimization tools in net zero energy buildings design, Energy and Buildings. 60 (2013) 110-124.

[45] R. Evins, A review of computational optimisation methods applied to sustainable building design, Renewable and Sustainable Energy Reviews. 22 (2013) 230-245.

[46] K. Peippo, P.D. Lund, E. Vartiainen, Multivariate optimization of design trade-offs for solar low energy buildings, Energy and Buildings. 29 (2) (1999) 189-205.

[47] M. Turrin, P. von Buelow, A. Kilian, R. Stouffs, Performative skins for passive climatic comfort, Automation in Construction. 22 (2012) 36-50.

[48] K. Shea, A. Sedgwick, G. Antonuntto, Multicriteria optimization of paneled building envelopes using ant colony optimization, Intelligent Computing in Engineering and Architecture. (2006) 627 - 636.

[49] W. Wang, H. Rivard, R. Zmeureanu, An object-oriented framework for simulation-based green building design optimization with genetic algorithms, Advanced Engineering Informatics. 19 (1) (2005) 5-23.

[50] L. Caldas, Generation of energy-efficient architecture solutions applying GENE_ARCH: An evolutionbased generative design system, Advanced Engineering Informatics. 22 (1) (2008) 59-70.

[51] C.E. Ochoa, M.B.C. Aries, E.J. van Loenen, J.L.M. Hensen, Considerations on design optimization criteria for windows providing low energy consumption and high visual comfort, Applied Energy. 95 (2012) 238-245.

[52] N. D’Cruz, A.D. Radford, J.S. Gero, A Pareto optimization problem formulation for building performance and design, Engineering Optimization. (1983) 37-41.

[53] K. Mela, T. Tiainen, M. Heinisuo, Comparative study of multiple criteria decision making methods for building design, Advanced Engineering Informatics. 26 (4) (2012) 716-726.

[54] L. Magnier, F. Haghighat, Multiobjective optimization of building design using TRNSYS simulations, genetic algorithm, and Artificial Neural Network, Building and Environment. 45 (3) (2010) 739-746.

[55] C.J. Hopfe, M.T.M. Emmerich, R. Marijt, J.L.M. Hensen, Robust multi-criteria design optimisation in building design, in: Proceedings of Building Simulation and Optimization, Loughborough, UK, 2012: pp. 118-125. 
[56] M. Hamdy, A. Hasan, K. Siren, Impact of adaptive thermal comfort criteria on building energy use and cooling equipment size using a multi-objective optimization scheme, Energy and Buildings. 43 (9) (2011) 2055-2067.

[57] G.P. Henze, J. Pfafferott, S. Herkel, C. Felsmann, Impact of adaptive comfort criteria and heat waves on optimal building thermal mass control, Energy and Buildings. 39 (2) (2007) 221-235.

[58] Building Performance Institute Europe (BPIE), Europe's buildings under the microscope - Country-bycountry review of the energy performance of Europe's buildings, 2011.

[59] J.L. Leyten, S.R. Kurvers, A.K. Raue, Temperature, thermal sensation and workers' performance in airconditioned and free-running environments, Architectural Science Review. 56(1) (2013) 41-21.

[60] Q. Jin, M. Overend, P. Thompson, Towards productivity indicators for performance-based façade design in commercial buildings, Building and Environment. 57 (2012) 271-281.

[61] W. Parys, Cost optimization of cellular office buildings based on building energy simulation, $\mathrm{PhD}$ Thesis, KU Leuven, 2013.

[62] A.D. Galasiu, J.A. Veitch, Occupant preferences and satisfaction with the luminous environment and control systems in daylit offices: a literature review, Energy and Buildings. 38 (7) (2006) 728-742.

[63] A.D. Radford, J.S. Gero, Tradeoff diagrams for the integrated design of the physical environment in buildings, Building and Environment. 15 (1) (1980) 3-15.

[64] C. Struck, P.J.C.J. de Wilde, C.J. Hopfe, J.L.M. Hensen, An investigation of the option space in conceptual building design for advanced building simulation, Advanced Engineering Informatics. 23 (4) (2009) 386-395.

[65] W. Tian, A review of sensitivity analysis methods in building energy analysis, Renewable and Sustainable Energy Reviews. 20 (2013) 411-419.

[66] A. Brownlee, J. Wright, Solution analysis in multi-objective optimization, in: Proceedings of Building Simulation and Optimization, Loughborough, UK, 2012: pp. 317 - 324. 
Figure 1: Schematic overview of the investigated office zone model. The position of the work plane (grey circle) is situated in the south-oriented half of the zone.

Figure 2: Schematic representation of the objective spaces from monthly optimizations.

Figure 3: Schematic representation of the newly created objective space and the corresponding annual Pareto front.

Figure 4: Scatter plot of results of annual optimization for the studied office model.

Figure 5: Scatter plots of all the available design solutions and fronts out of optimization process conducted for April (A) and August (B).

Figure 6: Comparison of the annual Pareto fronts for the static and adaptive facades. The pink dots represent the cloud of available solutions for the case of the adaptive facade.

Figure 7: Optimum window-to-wall ratio of monthly adaptive facades for the case study office building in the Netherlands (Points A to C are indicated in Figure 6).

Figure 8: Optimum properties of monthly adaptive facades for the case study office building in the Netherlands.

Figure 9: Bubble plots of all the design solutions evaluated in the optimization process for the month of April, with colors based on the values for (a) thermal conductivity and (b) specific heat capacity. 